\title{
Cormorant predation on PIT-tagged lake fish
}

\author{
Christian SKOV,${ }^{1 *}$ Niels JEPSEN,${ }^{1}$ Henrik BAKTOFT, ${ }^{1}$ Teunis JANSEN, ${ }^{2}$ Stig PEDERSEN, ${ }^{1}$ Anders KOED ${ }^{1}$ \\ ${ }^{1}$ National Institute of Aquatic Resources, Technical University of Denmark (DTU-Aqua), Vejlsøvej 39, Silkeborg; ${ }^{2}$ National Institute \\ of Aquatic Resources, Technical University of Denmark (DTU-Aqua), Charlottenlund Castle, Charlottenlund, Denmark \\ *Corresponding author: ck@aqua.dtu.dk
}

\begin{abstract}
The present study use data from recovered PIT (Passive Integrated Transponder) tags to explore species-and size-specific annual predation rates by cormorants on three common lacustrine fishes (size range 120-367 mm) in a European lake; roach (Rutilus rutilus), common bream (Abramis brama) and perch (Perca fluviatilis). In addition, we quantify the level of age/size truncation that cormorant predation could introduce in a population of perch, an important fish for recreational angling as well as for trophic interactions and ecosystem function in European lakes. Based on three years of PIT tagging of fish in Lake Viborg and subsequent recoveries of PIT tags from nearby cormorant roosting and breeding sites, we show that cormorants are major predators of roach, bream and perch within the size groups we investigated and for all species larger individuals had higher predation rates. Perch appear to be the most vulnerable of the three species and based on a comparison with mortality estimates from lakes without significant avian predation, this study suggest that predation from cormorants can induce age/size truncation in Lake Viborg, leaving very few larger perch in the lake. This truncation reduces the likelihood of anglers catching a large perch and may also influence lower trophic levels in the lake and thus turbidity as large piscivorous perch often play an important structuring role in lake ecosystem functioning.
\end{abstract}

Key words: avian predation, Perca fluviatilis, Abramis brama, Rutilus rutilus, PIT tags, mortality.

Received: February 2013. Accepted: October 2013.

\section{INTRODUCTION}

With the growing population of great cormorants $P h a-$ lacrocorax carbo sinensis throughout Europe, conflicts between fisheries and conservation have intensified. In many countries recreational and commercial fishers claim that cormorants cause severe damage to the fishing and the fish populations (Koed et al., 2006; Steffens, 2011; Klenke et al., 2013). The significance of cormorant predation on fish in restricted areas like ponds (Adamek et al., 2007), or pound nets, can readily be established (Dieprink, 1995), whereas the overall effect on natural fish populations is very difficult to estimate. Disentangling the different factors regulating fish populations is a well-tested, work demanding and often disappointingly futile exercise (Draulans, 1988; Keller, 1997). However, managers and politicians need documentation of the effects of predation to mitigate the conflicts (Rauschmayer et al., 2008; Behrens et al., 2008). Thus, several studies on the effects of cormorant predation have been carried out. Most of these have been based on diet analyses using hard parts (otoliths) found in cormorant pellets and despite providing information on the diet of cormorants, methodological problems make it difficult to quantify the predation and even harder to evaluate the effect on a fish population of unknown size (McKay et al., 2003). An alternative approach is to tag a high number of fish and then try to recover tags from the cormorant colonies or roosting sites. This has been done using PIT
(Passive Integrated Transponder) tags, coded wire tags, radio tags and carlin tags (Feltham and MacLean, 1996; Collins et al., 2001; Koed et al., 2006; Sebring et al., 2010; Jepsen et al., 2010).

Some studies suggest that the increasing abundance of cormorants has caused long-term declines of local fish populations (Lantry et al., 2002; Rudstam et al., 2004; Koed et al., 2006; Jepsen et al., 2010; Fielder, 2010). Other investigations from both lake and open coastal ecosystems found cormorants to have a low impact on fish communities and fisheries (Linn and Campbell, 1992; Engström, 2001; Barks et al., 2011; Lehikoinen et al., 2011; Östman et al., 2012). The lack of consensus between results from different studies is a clear sign of the level of complexity of this issue and to enable predictions about the effect of cormorant predation we need to better understand the complex predator-prey relations involved. Numerous studies of the diet of cormorants have provided a basic knowledge of prey species, prey size and seasonal trends in predation pressure. Adult cormorants eat from 250 to $1450 \mathrm{~g}$ of fish/day (Gremillet et al., 2003). Cormorants have not only a wide species range of prey, but also a wide size range. Cormorants eat very small items, such as shrimp and juvenile fish, but also large fish up to $1.5 \mathrm{~kg}$ (own observations). The issue of cormorants showing distinct prey preferences is very difficult to investigate, but a review of published diet studies gives the impression that these birds eat every- 
thing they can catch and swallow (Klenke et al. 2013). Hence the size distribution of prey fish mainly reflects whatever is available for the cormorants to catch. Others argue that the cormorant is an opportunist predator, catching the easiest prey, not necessarily the most abundant (Čech and Vejř́ik, 2011).

The objective of the present study is to use data from recovered PIT tags to explore species- and size-specific annual predation rates by cormorants on PIT-tagged lacustrine fishes. Since PIT tagging of smaller fish may infer detrimental effects on tagged individuals we focus only on fish above $120 \mathrm{~mm}$. More specific, data from three years tagging and subsequent recoveries is used to i) analyse annual differences in species- and size-specific predation rates for three common species in European lakes: roach (Rutilus rutilus), common bream (Abramis brama) and perch (Perca fluviatilis); and to ii) quantify the level of age/size truncation that cormorant predation could introduce in perch, an important fish for angling as well as for trophic interactions and ecosystem function in European lakes.

\section{METHODS}

\section{Study site}

The study took place in Lake Viborg (56 $26^{\prime} 58.74 \mathrm{~N}$, $9^{\circ} 25^{\prime} 17.98$ E) (Fig. 1). Lake Viborg consists of two basins, a northern part which is slightly bigger, deeper and less eutrophic than the southern (Tab. 1). The two basins are connected by a $50 \mathrm{~m}$ long and a $6 \mathrm{~m}$ wide canal allowing fish to disperse freely between the basins.

\section{Fish tagging}

Fish were sampled by seining in both lake basins and immediately after capture transferred to holding pens placed in shallow water at the lakeside. Here fish were kept until tagging 6-12 hours later. Fish were PIT tagged according to Skov et al. (2005) by surgically implanting a TIRIS Passive Integrated Transponder (PIT) tag (Texas Instruments, RI-TRP-RRHP, half duplex, $134 \mathrm{kHz}, 23.1$ $\mathrm{mm}$ long, $3.85-\mathrm{mm}$ diameter, $0.6 \mathrm{~g}$ in air) into the body cavity of the fish. In short, the fish were anesthetised and the tag inserted through a small incision made on the left
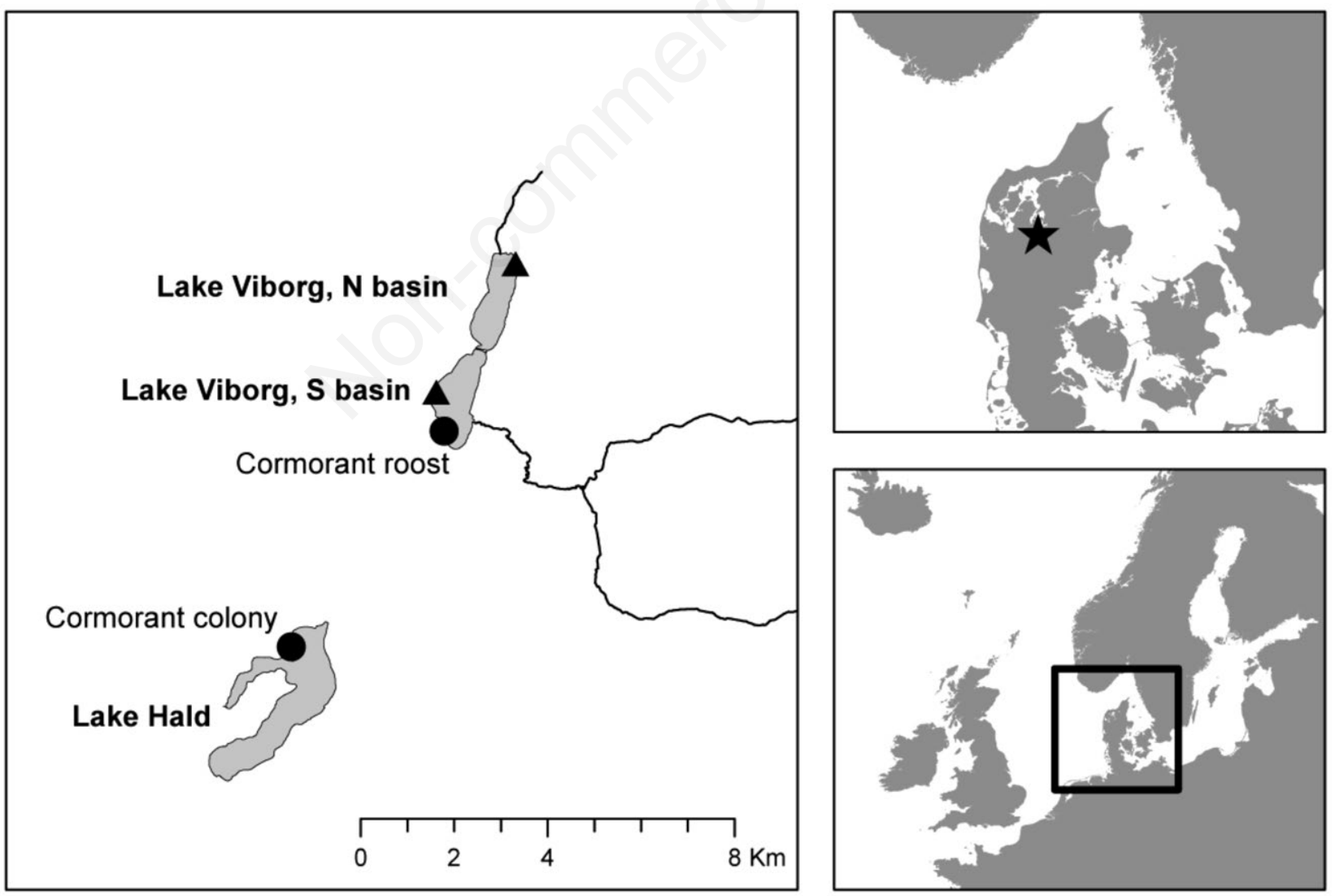

Fig. 1. Map of study site. Triangles represent the release sites for the tagged fish in the two basins. The breeding colony at Lake Hald consisted of 174, 252 and 188 nests in 2008, 2009 and 2010, respectively. 
side of the fish below the sideline slightly posterior to the pelvic fin. After recovery from anaesthesia the fish were released. For roach an evaluation of PIT tagging techniques has shown that the method causes no significant effect on survival or fish well-being i.e., body condition (Skov et al., 2005). Experimental animal treatment was performed in accordance to the guidelines described in permission (2012-DY-2934-00007) from the Danish Experimental Animal Committee.

Fish were captured and tagged every autumn in late September/early October. In 2008, 2009 and 2010 a total of 422, 336, 293 roach, 132, 82, 82 bream and 129, 19, 130 perch, were tagged respectively. For bream, only fish below $600 \mathrm{~g}$ were included as fish above this size were considered uneatable for cormorants. This is based on the fact that although several bream above $600 \mathrm{~g}$ were PIT tagged only PIT tags from fish up to $565 \mathrm{~g}$ were recovered. Maximum weights of tagged roach and perch were $430 \mathrm{~g}$ and $476 \mathrm{~g}$ respectively and all sizes of roach and perch from $120 \mathrm{~mm}$ up to these maximum sizes were PIT tagged. Minimum-maximum (mean) tag to fish weight ratio varied between $0.13-3.35 \%(0.90 \%), 0.10-3.11 \%$ $(0.72 \%)$ and $0.13-2.42 \%(1.05 \%)$ for roach, bream and perch, respectively, but with the majority of tags well below the often recommended 2\% threshold (but see Jepsen et al., 2004).

\section{PIT tag recovery}

Mortality estimates were based on PIT tags recovered by scanning the cormorants roosting place at the lake side and at a nearby cormorant breeding colony positioned 5.6 $\mathrm{km}$ from the lake (Fig. 1). A more distant breeding colony $39 \mathrm{~km}$ away and a roosting place $27 \mathrm{~km}$ away were also searched for PIT tags on several occasions during the

Tab. 1. Morphometric and physiochemical data for Lake Viborg in 2005 (Johansson et al., 2006).

\begin{tabular}{lcc}
\hline & Northern basin & Southern basin \\
\hline Area (ha) & 123 & 146 \\
Water volume (mill. M ${ }^{3}$ ) & 8.6 & 5.0 \\
Average depth (m) & 7.0 & 3.4 \\
Max depth (m) & 12.2 & 6.5 \\
Retention time (days) & $217-316$ & $99-129$ \\
Chlorophyll a (ug/L) & 50 & 58 \\
Suspended solids (mg/L) & 7.2 & 14.2 \\
Total-P (mg/L) & 0.098 & 0.215 \\
Total-N (mg/L) & 1.57 & 1.29 \\
Secchi depth (cm) & 270 & 106 \\
Coverage of submerged plants (\%) & 2.5 & 0.004 \\
Macrophyte depth limit (m) & 2.3 & 0.4 \\
Number of different submerged & 10 & 4 \\
macrophyte species & & \\
\hline
\end{tabular}

study period, and two tags were recovered from these breeding colonies. There are no other known cormorant roosting places in the vicinity of the lake. For recovery of the PIT tags a battery powered, portable and hand operated antenna system was used. The system consists of a circular antenna, with a diameter of $38 \mathrm{~cm}$ with 4 turns constructed from 9-gauge plastic coated (multistrand) oxygen free copper wire, mounted on wooden poles. The antenna is connected to a control module and an antenna reader frequency module (the two mounted together), a separate antenna tuning module (all Texas Instruments Series 2000) and a data logger recording the ID of tags read. The antenna has a maximum detection distance through air of 60-72 $\mathrm{cm}$ depending on orientation of the tag. Tags were allowed to accumulate, i.e. no tags were removed from the breeding colony or the roosting place during the study. The mean efficiency in recovering tags at the Lake Hald colony (Fig. 1) has been calculated to $78 \%$ (Boel, 2012).

PIT tag recovery in the breeding colony and the roosting site was done by systematically scanning the entire area with the portable antenna. Predefined and marked transects helped keeping track of the progress and securing that no area was missed. The roosting site consisted of a group of dead trees at the shore of Lake Viborg with an area of app. $1065 \mathrm{~m}^{2}$, about half of which is in the lake littoral zone. The breeding colony is in a group of trees, located on a peninsula at Lake Hald (Fig. 1).The branches from the trees where the cormorants nest, partly overhang the water. Therefore, data recovery also included scanning the nearshore areas around the colony. The area that was searched for PIT tags at the breeding colony was approx. $1650 \mathrm{~m}^{2}$. Scanning both areas took about eight hours on each occasion. During the breeding period we only scanned a part of the colony in order to minimize disturbance of the nesting birds. Hence the estimate of predation is based on a combination of data from the roosting site, data from whole colony scans and from scanning during the breeding season from only a part of the colony (Tab. 2).

\section{Data analysis on species and size specific differences}

Preliminary graphical analysis indicated a species specific non-linear effect of fish length on individual predation risk. Consequently, data was analysed using a binomial generalized additive model (binomial GAM) approach to estimate the cormorant predation risk on individual fish. Specifically, predation risk of individual fish was analysed as a non-linear function of body length (using smoothing functions), fish species (factor) and the two-way interaction between these. Additionally, year was included as a factor to allow for potential between-year variation in overall cormorant predation. In summary, the following initial model was fitted to the data:

$$
\operatorname{Pred}_{\mathrm{ij}}=\alpha+\text { species }_{\mathrm{i}}+\mathrm{f}_{\mathrm{i}}(\text { length })+\text { year }_{\mathrm{j}}+\varepsilon
$$


in which $\alpha$ is the common intercept; species is a three level factor (levels: perch, bream and roach); f(length) indicate species-specific smoothing functions, modelling the species-specific effect of length (penalized regression splines, smoothing parameters estimated using the Un-Biased Risk Estimator criterion (Wood, 2006)); year is a three level factor; and $\varepsilon$ is the error term. A logit link function was used. Parsimonious model selection was performed by stepwise single term elimination of non-significant terms $(\mathrm{P}>0.05)$. Significance of model terms was tested using analysis of residual deviance from single term deletions according to Wood (2006). Statistical analysis was performed in $\mathrm{R}$ version 2.15.0 ( $\mathrm{R}$ Development Core Team, 2012) using the mgcv-package version 1.7-13 (Wood, 2006).

\section{Effect on size distribution and abundance of the perch population}

To investigate the effect of cormorant predation on the perch population size and structure we used a simple age based population model:

$$
N_{a+1}=N_{a} e^{Z}
$$

Where $N$ is the abundance at age $a$ and $Z$ is the total mortality (Jennings et al., 2001). We parameterized four instances of this model type to simulate four different mortality scenarios. The first two baseline scenarios reflected situations without cormorants where the main source of perch mortality was predation by pike. $\mathrm{Z}$ in these models was estimates from Loch Davan (0.12) and Loch Kinord (0.29) (Treasurer et al., 1992). The third scenario was based on the cormorant predation rates obtained from the GAM model in the present study. The final scenario included both the cormorant predation from scenario \#3 as well as other sources of natural mortality assumed to equal average $\mathrm{Z}$ from Loch Davan and Kinord (0.205). As we have no data of the predation rate of untagged fish and aim for a conservative estimate, we assumed no cormorant predation on perch outside the age range of 2 to 9 years (corresponding to the tagged size range from $120 \mathrm{~mm}$ to $476 \mathrm{~g}$ ). Recruitment into the population model at the age of 2 , was set to 200 individuals. Hereby the total population size under the mortality scenarios excluding cormorant predation $(\mathrm{Z}=0.12$ or 0.29 ) equalled $800-1500$ perch ha $^{-1}$, which is a plausible natural density (Thorpe, 1977).
The size structures resulting from the four models were furthermore evaluated from a sports fishing perspective, by calculating and comparing the number of trophy perch $(>1$ $\mathrm{kg}$ ) in the lake. A perch of $1 \mathrm{~kg}$ was estimated to have an age of 12 years, based on the length-weight relation from this study (Length $(\mathrm{cm})=0.0055 \mathrm{x}$ weight. $\left.(\mathrm{g})^{3.35}\right)$ and the age-length relation from Lake Esrum (Skov, unpublished data), a less eutrophic lake than Lake Viborg.

\section{RESULTS}

\section{Species and size-specific differences}

In total, 48 visits to the cormorant nesting and roosting colonies were conducted to detect tags from predated PITtagged fish (Tab. 2). In total 277 PIT tags (17\%) from the 1625 tagged fish were subsequently recovered (45 bream, 159 roach and 73 perch) and an average of $15 \%$ bream, $15 \%$ roach and $26 \%$ perch were predated annually (Fig. 2 ). The GAM final model revealed a significant species specific effect of body length on individual predation risk $\left(\chi^{2}=60.323, \mathrm{df}=5.63, \mathrm{P}<0.0001\right)$. Generally, larger fish had a higher individual risk of predation, e.g., according to the GAM-analysis, perch between 240 and $300 \mathrm{~mm}$ on av-

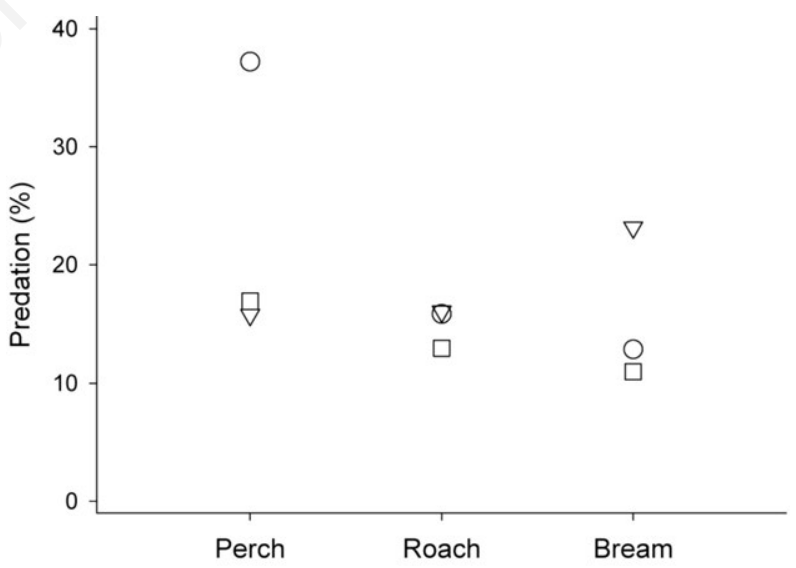

Fig. 2. Predation by cormorants (in percentage) on roach, bream and perch during the three study years (circle 2008, triangle 2009, square 2010).

Tab. 2. PIT-tag recovery protocol for the three study years on the ground below the resting place and the breeding colony. In some months two recovery surveys were conducted and this is also indicated. Predation estimates from 2008 are based on all recoveries from October 2008 to October 2009. See text for further explanation.

\begin{tabular}{|c|c|c|c|c|c|c|c|c|c|c|c|c|c|c|}
\hline & Sept & Oct & Nov & Dec & Jan & Feb & March & April & May & June & July & August & Sept & Oct \\
\hline $2008 / 2009$ & Tagging & & & $\mathrm{T}, \mathrm{R}$ & & & $\mathrm{T}$ & $\mathrm{P} * 2$ & $\mathrm{P} * 2$ & $\mathrm{P} * 2$ & & $\mathrm{~T}$ & & $\mathrm{~T}, \mathrm{P}, \mathrm{R}$ \\
\hline $2009 / 2010$ & Tagging & $\mathrm{T}, \mathrm{P} ; \mathrm{R}$ & & & & & T,P & $\mathrm{P}, \mathrm{R}$ & $\mathrm{P} * 2$ & $\mathrm{P}$ & $\mathrm{P}$ & $\mathrm{T} ; \mathrm{R}$ & & $\mathrm{T}, \mathrm{P}, \mathrm{R}$ \\
\hline 2010/2011 & Tagging & $\mathrm{T}, \mathrm{P} ; \mathrm{R}$ & $\mathrm{T} ; \mathrm{R}$ & $\mathrm{T}, \mathrm{R}$ & & $\mathrm{P} ; \mathrm{R}$ & $\mathrm{T}, \mathrm{P}$ & $\mathrm{P} * 2$ & $\mathrm{P} * 2$ & $\mathrm{P} * 2$ & & & $\mathrm{~T}$ & $\mathrm{~T}$ \\
\hline
\end{tabular}

T, PIT tag recovery from the entire breeding colony; $R$, resting place; P, PIT tags recovery from only a part of the colony. 
erage suffered above $50 \%$ risk of predation (e.g., 240 mm: 53\%; 95\% conf. int. 38\%-69\%; 300 mm: 57\%; 95\% conf. int. $31 \%-80 \%$ ); with maximum risk at $270 \mathrm{~mm}$ (71.5\%; 95\% conf. int. 51\%-86\%) (Fig. 3). However, for perch and bream the predation risk decreased for individuals larger than a given threshold length (perch: $\sim 270$ $\mathrm{mm}$; bream: $\sim 300 \mathrm{~mm}$ ). This pattern was not evident for roach (Fig. 3). The main effect year was not significant $\left(\chi^{2}=3.32, \mathrm{df}=2.04, \mathrm{P}=0.196\right)$, indicating that betweenyear variation was negligible and therefore excluded from the final model.

\section{Effect on size distribution and abundance of the perch population}

As compared to a system with supposedly relative low avian induced mortality (Loch Davon and Loch Kinord; $\mathrm{z}=0.12$ and 0.29 , Treasurer et al., 1992) the cormorant predation induced a clear age- and size truncation in the population (Fig. 4, Tab. 3). Thus, the number of perch $>1 \mathrm{~kg}$ (age 12 and older) was several orders of magnitude lower when the population was exposed to a high mortality rate as seen in Lake Viborg compared with the Scottish lochs with low natural mortality. Moreover, if the mortality

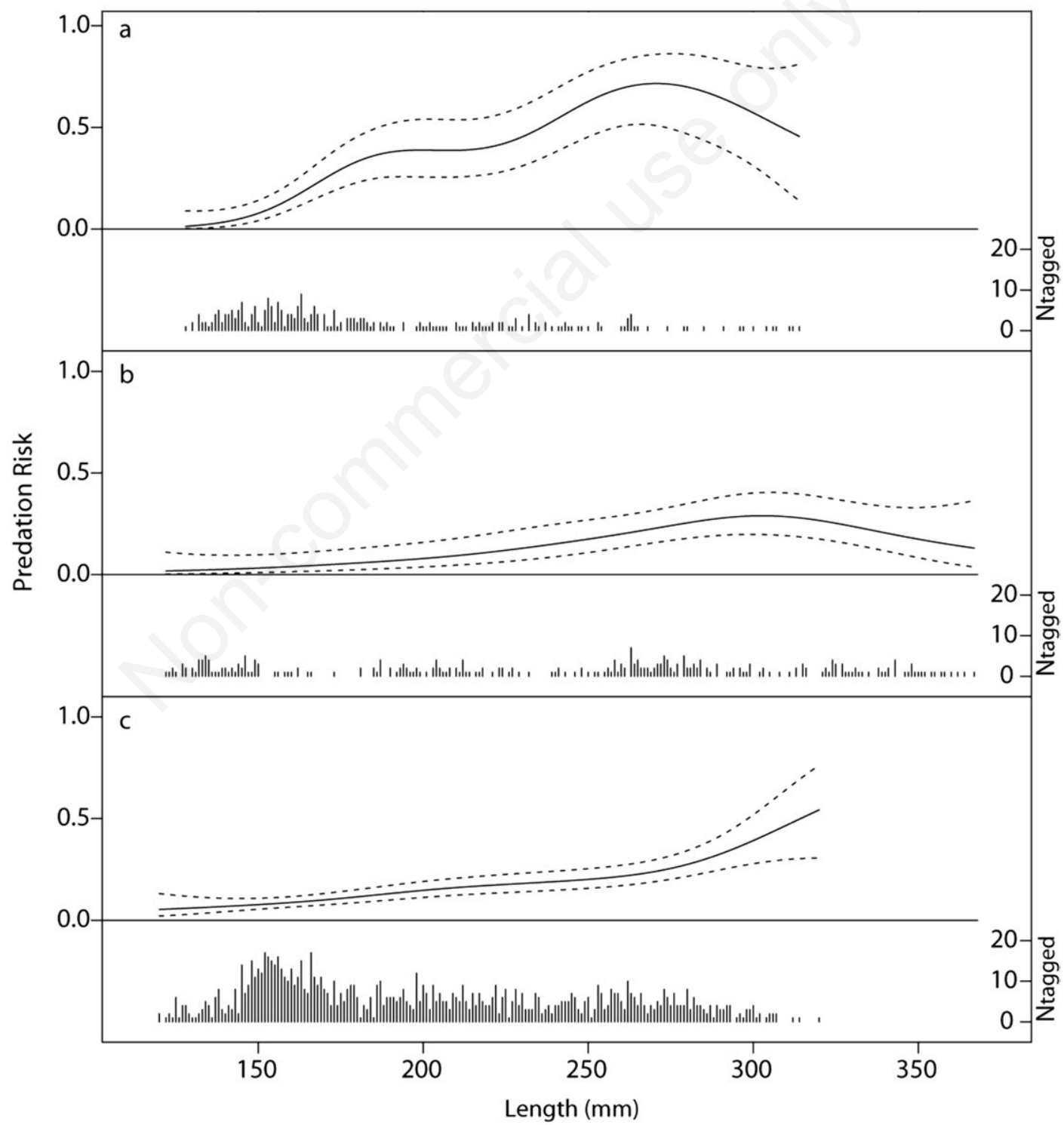

Fig. 3. Predation risk (and $95 \%$ confidence intervals) as a function of length for perch (a), bream, (b) and roach (c). Data are predicted values (back-transformed to original scale) obtained from the optimal GAM model: Pred $_{i j}=\alpha+\operatorname{species}_{i}+f_{i}($ length $)+$ year ${ }_{j}+\varepsilon$. Number of tagged fish at each length are given as vertical bars. 
caused by the cormorants was not the sole cause of mortality on the perch population in Lake Viborg, i.e., an additional instantaneous mortality of 0.2 was added (scenario 4), then the age truncation was even stronger (Fig. 4, Tab. 3). Specifically, the number of perch $>1 \mathrm{~kg}$ per ha was $351.8,40.4,18.9$ and 1.4 in scenario $1,2,3$ and 4, respectively (Tab. 3).

\section{DISCUSSION}

In this study, cormorants were shown to be a major predator of lake fish. Roach and bream seemed less vulnerable than perch, but still an average of around $15 \%$ of the tagged population was predated annually. For perch, the average annual predation was above $25 \%$ of the tagged population. This add to the growing body of evidence that percids (Perca spp.) are particularly vulnerable to cormorant predation (Lantry et al., 2002; Eschbaum et al., 2003; Rudstam et al., 2004; Fielder, 2010; Vetemaa et al., 2010; Bacheler et al., 2011; Emmrich and Duettmann, 2011, Östman et al., 2012, but see Diana et al., 2006). The underlying reason for the apparent preference for perch could be related to the behaviour of the fish in terms of flight response (Cosolo et al., 2010). Similar to species like grayling (Thymallus thymallus), that has been described as stupid in its response to foraging cormorants (Čech and Vejrík, 2011), we suggest that perch have a slower/weaker flight or hide response than roach or bream. Lab studies have shown that roach can be more alert towards predation than perch, i.e., when exposed to a threat they exhibit escape behaviour at an earlier stage than perch (Ranaker, 2012). Clearly further studies should be conducted to clarify the mechanisms behind this apparent vulnerability of perch.

Several studies have shown a dominance of small sized fish (i.e., young-of-the-year) in the diet of cormorants (Emmrich and Düttmann, 2011), or fish below $15 \mathrm{~cm}$ (Diana et al., 2006). As we could only tag fish above 120 $\mathrm{mm}$, no information about predation rates on smaller individual is available from this study. Among the tagged fish there was an increased predation of larger specimen, e.g., perch $>240 \mathrm{~mm}$ had annual average predation rates above $50 \%$. For perch and bream the predation risk seemingly dropped at lengths above a given threshold. This could be an effect of cormorant mouth size limitation and/or size specific preferences as larger fish generally will be more difficult to handle for the cormorant. However, it should be noted that the relatively low numbers of tagged large fish (e.g., perch above $260 \mathrm{~mm}$ ) results in a higher degree of uncertainty in the estimated predation risk, as indicated by the widening of the $95 \%$-confidence intervals towards the larger fish (Fig. 3). Consequently, this should be considered when interpreting the results.

The lower predation on the smallest tagged individuals could be caused by competition between piscivorous fish

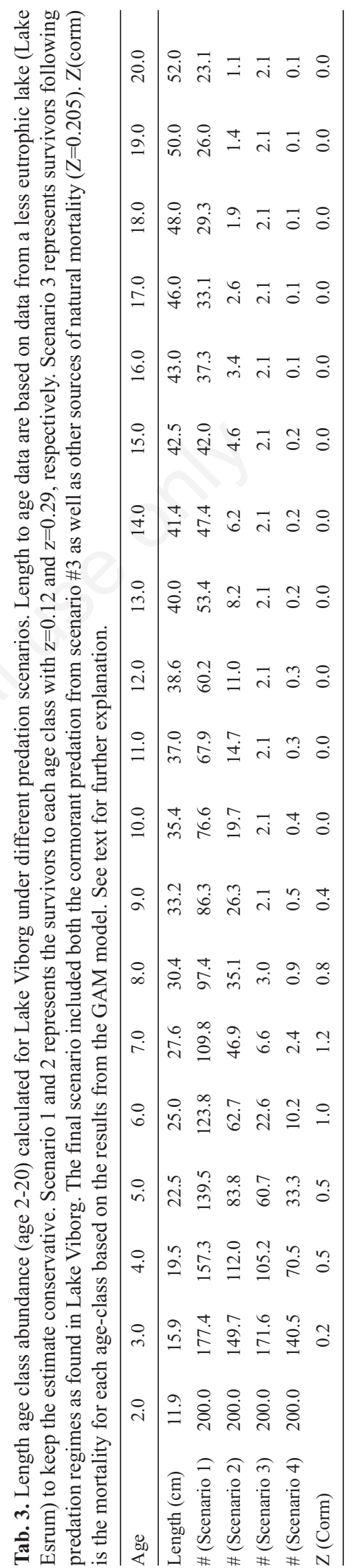


and cormorants. Thus, the smaller prey fish can be target for a wider range of length classes among the gape-size limited piscivores fish in the lake, and as the tagged fish grow, this competition is relaxed as fewer and fewer piscivorous fish in the lake are able to handle and swallow them. Finally, it is also possible that the cormorants simply maximize their energy budget by aiming at large sized fish. Based on studies of hard parts from cormorant pellets Čech et al., 2008 concluded that Great Cormorants select for larger fish in winter whereas in summer they consume all fish of appropriate size that they are able to catch. Hence if the majority of the predation in our study took place during winter, a selection for larger specimen could be explained. However due to the seasonal differences in sampling procedure, i.e. during summer only part of the colony was searched to minimise disturbance of roosting birds, it was not possible to fully investigate size specific seasonal differences.

\section{Predation on perch and its management implications}

Lake Viborg is an urban lake and clearly under strong human influence. The lake ecosystem has been enriched by nutrients from the municipality of Viborg over several decades which have led to eutrophication of the lake. Especially the shallow southern part has low water visibility due to phytoplankton blooms and hence lack of submerged vegetation. Although actions have been taken to reverse this eutrophication, to date no clear effect has been seen (Johansson et al., 2006). Another anthropogenic impact comes from anglers targeting pike (Esox lucius),

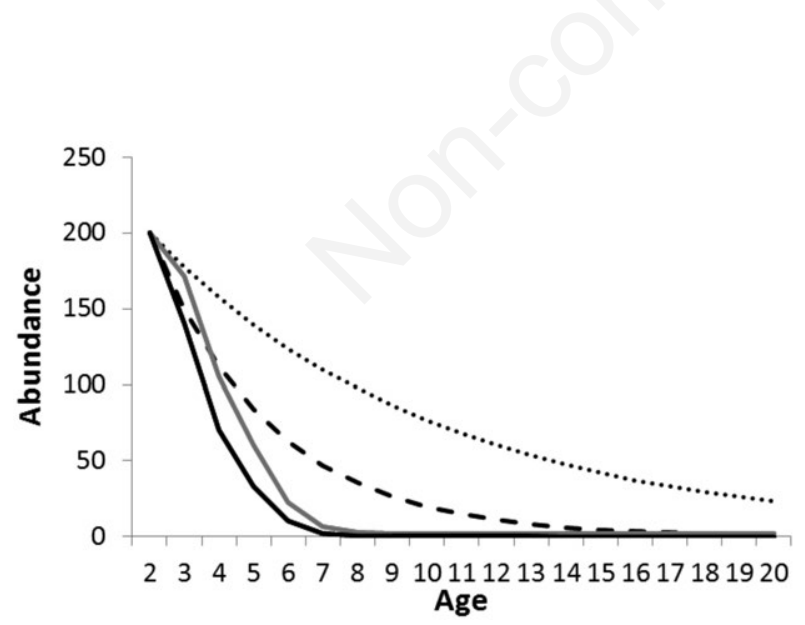

Fig. 4. Abundance to age curves for the four different mortality scenarios. Estimates of instantaneous mortality of perch from Scottish lakes with relative low natural mortality (scenario 1; dotted $(Z=0.12)$ and scenario 2 ; dashed $(Z=0.29)$ lines $)$ and minimum estimates of $z$ from cormorant predation in Lake Viborg on its own (scenario 3; grey line) and the additive effect of cormorant predation in Lake Viborg in addition to a natural instantaneous mortality of 0.2 (scenario 4 ; black line). A perch of $1 \mathrm{~kg}$ is likely to have an age of 12 years. perch and pikeperch (Sander lucioperca). The apparent age truncation on the perch population inferred by the cormorants may influence both angling as well as lake ecosystem dynamics i.e., turbidity.

Recreational fishing can have important socioeconomic impacts for example in terms of economy and human health (Aas et al., 2008). Likewise, perch is a valuable species for anglers on Lake Viborg and based on the results presented here, it is likely that the cormorant predation at Lake Viborg influence the anglers' chance of catching preferred trophy sizes i.e., perch above $1 \mathrm{~kg}$. Without cormorants in the system, the number of potential predators to eat the larger perch would have been lower as only very large pike and pikeperch are able to eat larger perch. This is somewhat confirmed by the Loch Lomond and Loch Davan study (Treasurer et al., 1992) where pike were the main predator on perch, the mortality of perch older than age 3 was very low. Indeed, compared to the mortality in Lochs Kinard and Davan (Treasurer et al., 1992), the predation rates from cormorants seen in our study results in a dramatic age/size truncation. In addition, if the perch experience other mortality causes than cormorant predation, i.e., predation from pike, perch or pike perch, the age truncation would be even higher. Clearly, since the lake is relative eutrophic, the abundance of large perch is generally low as food competition between roach and perch in eutrophic lakes infer slow growth of perch (Persson and Greenberg, 1990) and often reduce the relative abundance of larger perch in eutrophic shallow lakes (Jeppesen et al, 2000). Still, the results presented here suggest that the relative few perch that manage to grow big in Lake Viborg are under strong predation pressure, which leaves even fewer fish for the anglers to catch. This is also reflected by the fact that despite intense fishing for perch during the 3-year study period, we never caught and tagged a perch above $500 \mathrm{~g}$ albeit larger perch are present as indicated by occasionally reported record perch caught by specialised anglers in the lake $(1.4 \mathrm{~kg}$ and $1.5 \mathrm{~kg}$ in 2008 and 2009, respectively).

The apparent age/size truncation of the perch population introduced by the cormorants could cascade to lower trophic levels in the lake. Large perch are important predators on zooplanktivorous fish (such as small roach and bream) (Dörner et al., 2003) and any reduction in piscivorous perch hence infer reduced predation pressure on zooplanktivores and this can result in cascading effects (Carpenter et al., 1985) such as decreased zooplankton density, increased density of planktonic algae and ultimately more turbid water. It could be argued that this lack of predation would be compensated by the cormorant predation on roach and bream that also is demonstrated by this study, but since this predation is skewed towards larger specimen who are more omnivorous/benthivorous than zooplanktivorous this argument is not fully valid. 


\section{Are predation rates underestimated?}

Based on the number of recovered tags we conclude that cormorants can play a role in population dynamics of lacustrine fish. It could be argued that the observed patterns are overestimated due to adverse effects of tagging making the tagged fish more prone to predation. However, studies have demonstrated that perch tagged with relatively larger tags than used in this study performed well (Baras et al., 2000; Jacobsen et al., 2002) and for most tagged fish, the tag/bodymass ratio was well below recommended threshold (Jepsen et al., 2002; 2004). In contrast we would argue that our results are in fact underestimating the real magnitude of the predation. Firstly, our results are only based on recovered PIT tags and thus are absolute minimum estimates. It is certain that a number of PIT tags are expelled at other places than where we searched. Secondly, it is likely that tags were missed during the recovery process, either because they were positioned out of range of the flatbed scanner or because PIT tag accumulation at the colony resulted in collisions of tag codes (Brännäs et al., 1994). As the number of PIT tags in the study area increases with time, the risk of PIT tag collisions increases with study period length. PIT tag studies in the vicinity of Lake Viborg, i.e., a study on brown trout in Lake Hald (Boel, 2012) and on lacustrine fishes in nearby Lake Loldrup (Skov et al., 2011; Skov et al., 2013) has most probably increased the collision risk since many tags from tagged cormorant prey fish from these locations also were expelled at the Viborg roosting and breeding sites. Detection efficiency for PIT tags in cormorant colonies has been reported to be in the range of 50-90\%, but averaging 57\% (Seabring et al., 2010), and specifically for the cormorant colony at Lake Hald, (Boel, 2012) estimated detection efficiency to $78 \%$. Finally, we excluded predation on individuals larger than $500 \mathrm{~g}$ from our age based models, as we did not capture and tag any of those and hence have no valid mortality estimates. It probably would have been more correct to include mortalities on perch between $500 \mathrm{~g}$ up to $1 \mathrm{~kg}$ a size which cormorants can handle and eat (Klenke et al., 2013), but we choose not to do this in order to present the most conservative estimate. However cormorants can indeed eat even larger perch and based on angler reports, these are rare but present in the lake. Hence including a cormorant induced mortality rate on these larger perch in the model would have increased the size truncation even further. Adding up, it seems clear that the data presented here are indeed conservative.

It is noteworthy that the colony from which most tags were located is situated at a neighboring lake $5.6 \mathrm{~km}$ from the study lake. Hence it is possible that predation would have been higher if the colony was positioned at the lake. This also implies that multiple lakes in the vicinity of colonies can be affected by predation from that colony.

\section{CONCLUSIONS}

Here we used data from recovered PIT tags to explore species- and size-specific annual predation rates by cormorants which implies some potential shortcomings. First of all it is only possible to evaluate predation rates on the tagged fish size spectrum, i.e., fish larger than $120 \mathrm{~mm}$. In addition we get no information about absolute predation rate but only relative predation rates. Hence future studies could benefit from combining PIT tag recoveries with other methods such as pellet analyses as well as density estimates of the population size of the prey fish. This would add to a more complete understanding of the potential impact of cormorant predation on fish populations.

Still, with this study, we have shown that cormorant is a major predator of lacustrine fish such as roach, bream and perch and unlike i.e., Engström (2001) we argue that cormorants do cause a change in the fish population. Within the size range analysed, there was higher predation on larger individuals for all species although for bream and perch, predation was reduced for the very largest individuals probably due to capture and/or handling constraints of the birds. Perch seems to be the most vulnerable of the three species which is in line with other studies. Based on a comparison with mortality estimates from lakes without avian predation, the cormorants induce age truncation, leaving very few larger perch in the lake. This truncation reduces the likelihood of anglers catching a large perch and could also influence lower trophic levels in the lake and thus water clarity as large piscivorous perch often play an important structuring role in ecosystem functioning.

\section{ACKNOWLEDGMENTS}

This project was funded by Danish National Fishing Licence Funds. We wish to thank students and technicians who helped to tag the fish and recover tags from the colonies and roosting places.

\section{REFERENCES}

Aas ØR, Arlinghaus RB, Ditton D, Policansky HL, Schramm JR, 2008. Global challenges in recreational fisheries. Blackwell Publishing, Oxford: 364 pp.

Adamek Z, Kortan J, Flajshans M, 2007. Computer-assisted image analysis in the evaluation of fish wounding by cormorant Phalacrocorax carbo sinensis (L.) attacks. Aquacult. Int. 15: 211-216.

Bacheler NM, Paoli TJ, Schacht GM, 2011. Controls on abundance and distribution of yellow perch: predator, water quality, and density-dependent effects. Trans. Am. Fish. Soc. 140:989-1000.

Baras E, Malbrouck C, Houbart M, Kestemont P, Melard C, 2000. The effect of PIT tags on growth and physiology of age- 0 cultured Eurasian perch Perca fluviatilis of variable sizes. Aquaculture 185:159-173. 
Barks PM, Doucette JL, Somers CM, 2011. Lack of anglingsized yellow perch in a Canadian boreal Lake: Potential influences of growth rate, diet and predation by double-crested cormorants. Trans. Am. Fish. Soc. 139:1029-1040.

Behrens V, Rauschmayer F, Wittmer H, 2008. Managing international 'problem'species: why pan-European cormorant management is so difficult. Environ. Conserv. 35:55-63.

Boel M, 2012. Life history types and strategies. Case studies on brown trout (Salmo trutta) and alewives (Alosa pseudoharengus), involving physiological differences and interspecific interactions. Ph.D. thesis, DTU Aqua.133 pp.

Brännäs E, Lundqvist H, Prentice E, Schmitz M, Brännäs K, Wiklund BS, 1994. Use of the passive integrated transponder (PIT) in a fish identification and monitoring system for fish behavioral studies. Trans. Am. Fish. Soc. 123: 395-401.

Carpenter SR, Kitchell JF, Hodgson JR, 1985. Cascading trophic interactions and lake productivity. Bioscience 35:634-639.

Čech M, Čech P, Kubečka J, Prchalová M, Draštík V, 2008. Size selectivity in summer and winter diets of great cormorant (Phalacrocorax carbo): does it reflect season-dependent difference in foraging efficiency? Waterbirds 31:438-447.

Čech M, Vejř́k L, 2011. Winter diet of great cormorant (Phalacrocorax carbo) on the River Vltava: estimate of size and species composition and potential for fish stock losses. Folia Zool. 60:129-142.

Collins K, Roby DD, Craig DP, Ryan BA, Ledgerwood RD, 2001. Colonial waterbird predation on juvenile salmonids tagged with passive integrated transponders in the Columbia River estuary: vulnerability of different salmonid species, stocks and rearing types. Trans. Am. Fish. Soc. 130: 385-396.

Cosolo M, Ferrero EA, Sponza S, 2010. Prey ecology and behaviour affect foraging strategies in the Great Cormorant. Mar. Biol. 157:2533-2544.

Diana JS, Maruca S, Low B, 2006. Do increasing cormorant populations threaten sportfishes in the great lakes? A case study in Lake Huron. J. Great Lakes Res. 32:306-320.

Dieperink C, 1995. Depredation of commercial and recreational fisheries in a Danish fjord by cormorants, Phalacrocorax carbo sinensis. Fisheries Manag. Ecol. 3:197-207.

Dörner H, Berg S, Jacobsen L, Hulsmann S, Brobjerg M, Wagner A, 2003. The feeding behaviour of large perch Perca fluviatilis (L.) in relation to food availability: a comparative study. Hydrobiologia 506:427-434.

Draulans D, 1988. The effectiveness of attempts to reduce predation by fish-eating birds - a review. Biol. Conserv. 41: 219-232.

Emmrich M, Duettmann H, 2011. Seasonal shifts in diet composition of Great Cormorants Phalacrocorax carbo sinensis foraging at a shallow eutrophic inland lake. Ardea 99:207-216.

Engström H, 2001. Long term effects of cormorant predation on fish communities and fishery in a freshwater lake. Ecography 24:127-138.

Eschbaum R, Veber T, Vetemaa M, Saat T, 2003. Do cormorants and fishermen compete for fish resources in the Väinameri (Eastern Baltic) area?, p. 72-83. In: I.G. Cowx (ed.), Interactions between fish and birds: implications for management. Blackwell Publishing Ltd., Oxford, UK.

Feltham MJ, MacLean JC, 1996. Carlin tag recoveries as an indicator of predation on salmon Salmo salar L. smolts by goosanders Mergus merganser L. and red-breasted mergansers M. serrator L. J. Fish Biol. 48:270-282.

Fielder DG, 2010. Response of yellow perch in Les Cheneaux Islands, Lake Huron to declining numbers of double-crested cormorants stemming from control activities. J. Great Lakes Res. 36:207-214.

Gremillet D, Wright G, Lauder A, Carss DN, Wanless S, 2003. Modelling the daily food requirements of wintering great cormorants: a bioenergetics tool for wildlife management. J. Appl. Ecol. 40:266-277.

Jacobsen L, Berg S, Broberg M, Jepsen N, Skov C, 2002. Activity and food choice of piscivorous perch (Perca fluviatilis) in a eutrophic shallow lake: a radio-telemetry study. Freshwater Biol. 47:2370-2379.

Jennings S, Kaiser M, Reynolds JD, 2001. Marine Fisheries Ecology. Blackwell Science. Oxford (UK): pp 432.

Jepsen N, Koed A, Thorstad EB, Baras E, 2002. Surgical implantation of telemetry transmitters in fish: how much have we learned? Hydrobiologia 483:239-248.

Jepsen N, Schreck C, Clement S, Thorstad E, 2004. A brief discussion of the $2 \%$ tag/bodymass rule., p. $255-259$. In: M.T. Spedicato, G. Marmulla and G. Lembo (eds.), Aquatic telemetry: advances and applications. FAO - COISPA, Rome, Italy.

Jepsen N, Sonnesen P, Klenke R, Bregnballe T, 2010. The use of coded wire tags to estimate cormorant predation on fish stocks in an estuary. Mar. Freshw. Biol. 61:320-329.

Jeppesen E, Jensen JP, Sondergaard M, Lauridsen T, Landkildehus F, 2000. Trophic structure, species richness and biodiversity in Danish lakes: changes along a phosphorus gradient. Freshwater Biol. 45:201-218.

Johansson LS, Søndergaard M, Liboriussen L, Jacobsen T, 2006. [State of the environment in Lake Viborg 1985-2005]. [Report in Danish]. Report no. 607, National Environmental Research Institution (NERI).

Keller T, 1997. Food of cormorants Phalacrocorax carbo wintering in Bavaria (southern Germany). Ekol. Pol. 45:237-238.

Klenke RA, Ring I, Kranz A, Jepsen N, Rauschmayer F, Henle K, 2013. Human - wildlife conflicts in Europe, fisheries and fish-eating vertebrates as a model case. Springer, New York: 347 pp.

Koed A, Baktoft H, Bak BD, 2006. Causes of mortality of Atlantic salmon (Salmo salar) and brown trout (Salmo trutta) smolts in a restored river and its estuary. River Res. Appl. 22:69-78.

Lantry BF, Eckert TH, Schneider CP, Chrisman JR, 2002. The relationship between the abundance of smallmouth bass and double-crested cormorants in the eastern basin of Lake Ontario. J. Great Lakes Res. 28:193-201.

Lehikoinen A, Heikinheimo O, Lappalainen A, 2011. Temporal changes in the diet of great cormorant (Phalacrocorax carbo sinensis) on the southern coast of Finland - comparison with available fish data. Boreal Environ. Res. 16:61-70.

Linn IJ, Campbell KLI, 1992. Interactions between whitebreasted cormorants and the fisheries of Lake Malawi. J. Appl. Ecol. 29:619-634.

McKay HV, Robinson KA, Carss DN, Parrott D, 2003. The limitations of pellet analysis in the study of cormorant Phalocrocorax spp. diet. Vogelwelt 124:227-236.

Persson L, Greeenberg, LA, 1990. Juvenile competitive bottle- 
necks: the perch (Perca fluviatilis)-roach (Rutilus rutilus) interaction. Ecology 71:44-56.

R Development Core Team, 2012. R: A language and environment for statistical computing. R Foundation for Statistical Computing, Vienna, Austria. Available from: http://www. R-project.org/

Ranaker L, 2012. Piscivore-prey fish interactions: consequences of changing optical environments. Ph.D. thesis, Lund University.

Rauschmayer F, Wittmer H, Berghofer A, 2008. Institutional challenges for resolving conflicts between fisheries and endangered species conservation. Mar. Policy 32:178-188.

Rudstam LG, VanDeValk AJ, Adams CM, Coleman JTH, Forney JL, Richmond ME, 2004. Cormorant predation and the population dynamics of walleye and yellow perch in Oneida Lake. Ecol. Appl. 14:149-163.

Sebring SH, Ledgerwood RD, Sandford BP, Evans A, Matthews GM, 2010. Detection of passive integrated transponder (PIT) tags on piscivorous avian colonies in the Columbia River Basin, 2008. NMFS \& NOAA report, Seattle, USA: 47 pp.

Skov C, Brodersen J, Bronmark C, Hansson L-A, Hertonsson P, Nilsson PA, 2005. Evaluation of PIT-tagging in cyprinids. J. Fish Biol. 67:1195-1201.

Skov C, Baktoft H, Brodersen J, Brönmark C, Chapman B,
Hansson L-A, Nilsson PA, 2011. Sizing up your enemy: individual predation vulnerability predicts migratory probability. P. Roy. Soc. B-Biol. Sci. 278:1414-1418.

Skov C, Chapman B, Baktoft H, Brodersen J, Brönmark C, Hansson L-A, Hülthen K, Nilsson PA, 2013. Migration confers survival benefits against avian predators for partially migratory freshwater fish. Biol. Lett. 9:20121178.

Steffens W, 2011. Great Cormorant Phalacrocorax carbo is threatening fish populations and sustainable fishing in Europe. Am. Fish. Soc. Symp. 75:189-200.

Thorpe J, 1977. Synopsis of biological data on the perch, Perca fluviatilis, and Perca flavescens. FAO Fisheries Synopsis 113.

Treasurer JW, Owen R, Bowers E, 1992. The population dynamics of pike, Esox lucius, and perch, Perca fluviatilis, in a simple predator-prey system. Environ. Biol. Fish. 34:65-78.

Östman Ö, Bergenius M, Boström MK, Lunneryd S, 2012. Do cormorant colonies affect local fish communities in the Baltic Sea? Can. J. Fish. Aquat. Sc. 69:1047-1055.

Vetemaa M. Eschbaum R, Albert A, Saks L, Verliin A, Jürgens K, Kesler M, Hubel K, Hannesson R, Saat T, 2010. Changes in fish stocks in an Estonian estuary: overfishing by cormorants? ICES J. Mar. Sci. 67:1972-1979.

Wood SN, 2006. Generalized additive models: an introduction with R. Chapman \& Hall/CRC: 410 pp. 